\title{
Accessibility Evaluation of Design Patterns on Moodle Mobile
}

\author{
Vitor Casadei $^{1}$, Luciana Zaina ${ }^{1}$, Eduardo Pinheiro ${ }^{1}$, Toni Granollers ${ }^{2}$ \\ ${ }^{1}$ Departamento de Computação - UFSCar - Campus Sorocaba \\ Rod. João L. dos Santos, Km 110 - SP-264, CEP 18052-780 - Sorocaba - SP - Brasil \\ ${ }^{2}$ University of Lleida \\ E.U.P. Avda. Jaume II 69, Lleida, Spain \\ \{vitor.casadei,edu.g.pinheiro\}@gmail.com, lzaina@ufscar.br, \\ antoni.granollerseudl. cat
}

\begin{abstract}
An universal accessibility evaluation of the Moodle Mobile app from a study with 21 participants without disabilities is presented by assessing the emotional response to seven interaction design patterns and video analysis. Results show accessibility barriers identified during the execution of activities and implications of these barriers in the learning process.
\end{abstract}

\section{Introduction}

In Brazil, the mobile market has grown rapidly in the last years: currently 93 million people own a smartphone, where 68 million use the device for Internet browsing [Nielsen 2016], this means that about a quarter of the population accesses the Internet through mobile devices. Another research indicates that the number of smartphones grew by $112 \%$ since 2010 in Brazil and it is expected a greater increase further by 2020 [Mazetto 2015].

In the academic area mobile devices present a great potential to improve the learning experience of any student by providing mobility and easy access to information alongside several benefits in one device and the Learning Management System (LMS) Moodle is one of the most adopted systems in the whole world: Moodle had been registered in more than 76000 sites over 230 countries with Brazil being the third country with more Moodle installations [Moodle.org 2016].

While the usual focus of web accessibility is to design for people with disabilities, research in accessibility also brings benefits to everyone, including people that do not have a disability, but have situational limitations, as limited bandwidth, older devices (with limited power) and small screens for example [Henry et al. 2014]. In this scenario, people who use mobile devices for educational purposes are affected by various factors, such as lack of adaptation of interface elements. For this purpose, Universal Design brings the process of creating solutions that comply with the needs of the widest possible range of situations and for all audiences.

In the educational context, many e-learning platforms are accessed through mobile devices and this change of perspective from desktop to mobile could mean another revolution in the way of learning and presenting information [Ally and Prieto-Blázquez 2014]. However, these e-learning systems are not well adapted to mobile usage and many have serious accessibility barriers [Brajnik 2008] that can discourage students and users of such platforms in the learning process. 
V Congresso Brasileiro de Informática na Educação (CBIE 2016)

Anais do XXVII Simpósio Brasileiro de Informática na Educação (SBIE 2016)

This goal of this study is to present the results of an accessibility evaluation of interaction design patterns on m-learning platforms from emotional assessment of users without disabilities in the mobile application for Moodle. In the evaluation 21 participants performed 5 tasks on the mobile application and we identified accessibility barriers related to some of the design patterns studied and the impact of these barriers in the learning experience of users without disabilities.

The 7 Design Patterns analyzed in this study were selected based on the 5 tasks performed by the users and on studies presented in Section 2. This study is a contribution to developers and designers that use such design patterns in their projects. As accessibility problems tend to affect the usability of an interface, when applied to e-learning systems, such problems can affect the learning process as well [Santana et al. 2014]. Finally, as we could not find other works on accessibility of Design Patterns on mobile devices, this is an important contribution to the HCI area.

\section{Theoretical Foundation and Related Works}

The theoretical foundation and works related to this study are mainly in the areas or Accessibility, Design Patterns, M-Learning and E-learning systems and Universal Design. In this section we present important works that served as basis or are related to this research in the topics described above.

The Web Accessibility Initiative (WAI) [Harper et al. 2014] of the World Wide Web Consortium (W3C) presents guidelines, strategies and resources related to accessibility in various contexts. However, some guidelines defined by W3C are not applicable or adapted to the mobile world and as the web become more mobile and ubiquitous, the need for accessibility in any context and device is urgent [Abou-Zahra et al. 2013].

Alongside the impairments and accessibility barriers that users encounter while using a website, their mood is directly related to the overall experience and the accessibility of a website or app is beneficial for everyone as it improves the usability for every user as shown in [Pascual et al. 2013] where a study was conducted with 13 participants that where blind or low-vision users and also users without disabilities. Also, people with disabilities are not the only ones that have problems using websites and mobile devices, as there is an exponential growth of the elderly population in the world that suffers from a wide variety of disabilities developed by the advanced age [Díaz-Bossini and Moreno 2013]

The concept of Design Pattern was developed with the goal of being components of language that could be used as dialog about organizations and development process. Design Patterns can be understood as best practices or some sort of heuristics of well knows design problems and its solutions as presented on [Hoober and Berkman 2011] in 76 general patterns organized in 13 categories, on [Sampaio 2013] in which a tool was developed to automatically adapt web site navigation menu in different devices according to common menu design patterns and on [Ribeiro and Carvalhais 2012, Ribeiro 2012] that presents a comparative analysis of some of the most known libraries in order to propose 21 Design Patterns for general purposes derived from studies in mobile and web design with the objective of helping designers and developers to design mobile and web interfaces.

Mobile Learning (M-learning) is an approach to e-learning where mobile devices are used to access educational content. Considering that traditional LMS were created 
V Congresso Brasileiro de Informática na Educação (CBIE 2016)

Anais do XXVII Simpósio Brasileiro de Informática na Educação (SBIE 2016)

before the dissemination of mobile devices with Internet access, there is a gap that has not been filled on exploring the application and adaptation of these systems on such devices as a way to motivate students to perform educational activities and in the exploration of new patterns of interaction [Guterres and Silveira 2015] as accessibility and usability studies have mainly been made on Moodle desktop [Barbosa et al. 2015, Santana et al. 2014].

Accessibility in e-learning is the ability of the learning environment to adjust to the needs of any learner with any disability [Jemni et al. 2014], which involves content presentation and interaction. Also, it's important to consider the impacts of mobile learning in the life of students and educators as presented by [Abachi and Muhammad 2014].

Universal Design is the process of developing a system or product that can be used by any person with any disability (or without disabilities), in any situation or environment. In HCI, Universal Design is mainly related to the development of computer systems for any person with any limitation [Henry et al. 2014]. It is important to point out that many accessibility barriers faced by people with disabilities also are witnessed by other users, however, for disabled people, accessibility is essential in order to actually have access to information, while for people with situational accessibility, this concern is mere convenience [Heumann 1998].

Existing standards and guidelines (such as WCAG from W3C) do not give clear instructions for designers on how to design accessible solutions nor give developers instructions on how to create accessible systems and as a result, in most situations, developers try to make a website accessible by fixing some issues at the end of the development, which tends to introduce accessibility gaps and increase costs in the final product [Newell and Gregor 1988].

\section{Accessibility Evaluation}

In this section we explain our methodology that was used in this research. The method consists in the execution of a controlled experiment [Lazar et al. 2010] composed of three phases: the Preparation, Execution and Analysis of the results.

\subsection{Participants}

Twenty one participants took part in the research on April 2016 where 56\% were female and $44 \%$ were male with ages varying from 19 to 24 years old. None of the participants had identified disabilities and all were undergraduate students and owned a smartphone. When asked about the experience using mobile devices (smartphones or tablets) $78 \%$ stated to have 4 or more years using a device and only $4.3 \%$ had two years of experience (the rest was in between). Also the daily usage (in hours) of mobile devices was around 2 to 8 hours and the daily usage of Internet around 2 to 5 hours.

Although all participants used their mobile device to access the Internet, only $30.4 \%$ actually preferred the mobile device over a PC to access web content and when asked to describe situations that influenced this preference we received many answers like "I can't find information or navigate in some websites", "The buttons are too small", "I can't understand the meaning of some icons in some sites" or "I have difficulties accessing my grades on the smartphone". Another important information is that all participants were users of Moodle and 48\% accessed up to 3 times a week and 13\% accessed Moodle daily in a mobile device. 
V Congresso Brasileiro de Informática na Educação (CBIE 2016)

Anais do XXVII Simpósio Brasileiro de Informática na Educação (SBIE 2016)

The participants were students of a chemistry class of the University blind-review in Brazil and were chosen randomly by volunteering to participate in the research. In this initial study we have chosen participants without disabilities in order to identify accessibility barriers in Design Patterns that affect such users using Moodle on a mobile device.

\subsection{Apparatus and Artifacts}

The experiment was performed in a laboratory of the Department of Informatics of the University blind review in Brazil. Five different Android devices were used (Nexus 5, Moto G, Moto E, Galaxy S4 and a Tegra Note tablet) with screen size varying from 4 to 7 inches and Android version 5 or above. All devices had the same keyboard configured with same layout and had the Moodle Mobile ${ }^{1}$ app installed.

The participants were seated in separate desks in the laboratory and each one received a copy of the Terms of Consent, an accompaniment questionnaire with the tasks description and a page with screenshots of Moodle Mobile for each task with enumerated elements of interface together with the mobile device connected to the Internet. Each participant was monitored by an observer that also had a form in which he would annotate important information about difficulties and problems that occurred during the experiment.

The Accompaniment Form consisted of five tasks 2 , in each task the participants would fill their satisfaction and feeling of dominance about some elements of interface that were highlighted in the page with Moodle Mobile screenshots. The observers were instructed to not interfere in the participant's interactions and the participants were told to try to perform all the tasks and only ask for help when strictly needed.

Before the test started, the users were asked to sign a Terms of Consent for image and data usage. They also filled another form where demographic and general information was collected. All sessions were recorded using the mobile app Lookback ${ }^{3}$ that records the screen interaction and sound and video from the front camera of the mobile device.

All 4 observers that participated in this study are master's students in the field of Human Computer Interaction and two of them had experience working with accessibility issues on mobile devices. The other two develop research in the usability area (also on mobile devices).

\subsection{Procedure}

The average time per user performing the five tasks was 25 minutes. In total 4 sessions were performed with 5 users per session and one final session with one participant only which means that all devices were used almost the same number of times. During the sessions, the participants were also advised to think aloud about their progress, doubts and problems while performing each task.

In the beginning of each sessions the participants were given general information about how to use the artifacts provided, how to fill the forms and what the tasks would be. It was given special attention to the explanation of the Self-Assessment Manikin (SAM).

\footnotetext{
$1 \longdiv { \text { www.download.moodle.org/mobile } }$

${ }^{2}$ The tasks are explained in more detail at https://ux-leris.github.io/vitor_casadei/sbie2016

$\sqrt[3]{\text { www.lookback.io }}$
} 
V Congresso Brasileiro de Informática na Educação (CBIE 2016)

Anais do XXVII Simpósio Brasileiro de Informática na Educação (SBIE 2016)

The SAM is a non-verbal pictorial assessment technique that aims to measure emotion in terms of satisfaction, arousal and dominance that are associated with the reaction of a person to some sort of stimuli [Bradley and Lang 1994]. The SAM technique used in this experiment aimed to capture only the satisfaction and dominance (other usability and User Experience metrics were not applied due to the fact that this is a first exploratory study) of the users on each element of interface that was actually used by the participant and the icon representation of both satisfaction and dominance was adapted as can be seen in Figure 1 .

The participants were advised to freely perform the tasks without any intervention or any tips on how to perform or screens that should be used. At the completion of each activity they would indicate their satisfaction and dominance of selected interface items that were highlighted and enumerated for each activity (the participants should do this only for the elements that they used during the task). On each task the participants were also asked to report any difficulties or problems of usage or understanding of any interface element and they were also asked to inform their level of agreement in a Likert scale on the number of steps and localization problems in the general execution of the task.

At the end of the experiment, each participant were asked to give feedback on the execution of the experiment and also about the satisfaction with the adaptation and usage of the Moodle e-learning system on mobile devices.

\subsection{Analysis}

By the end of the sessions we had collected the satisfaction and dominance emotion of each participant related to the studied elements that were mapped to mobile interaction design patterns using the list of patterns from [Hoober and Berkman 2011] and [Ribeiro and Carvalhais 2012]. Using design patterns is useful because there is no dependency on the context or application and being so, it's possible to use this methodology on any other application and achieve related data that can be easily compared. The use of design patterns is also beneficial because the findings can be applied to other interfaces that use the same patterns.

The data collected from the SAM questionnaire was grouped into seven design patterns that are Toggle Menu, Icon, Infinite List, Vertical List, Input Area, Button and Form Selection ${ }^{4}$ and are presented in Figure 1 in two bubble charts: one for satisfaction and another for dominance.

The sessions also had another output, which are the recording of screen and front camera video of the mobile devices. In the beginning of each session a recording was started and terminated at the end and, in doing so, it was possible to analyze in deeper details the interaction of the participants with the Moodle Mobile app and identify actions that could not be perceived by the observer during the session.

In order to catalog and analyze the recordings we used the Communicability Evaluation Method (CEM) tags [Capelão et al. 2011] as communicability directly impacts in the understanding of the user about the interface and therefore in accessibility. We did not use the whole method, but only used the tags in order to identify accessibility problems during the interaction with the interface that are presented as communicability ruptures.

\footnotetext{
${ }^{4}$ More details on the Design Patterns can be found at https://ux-leris.github.io/vitor_casadei/sbie2016
} 
V Congresso Brasileiro de Informática na Educação (CBIE 2016)

Anais do XXVII Simpósio Brasileiro de Informática na Educação (SBIE 2016)

The choice for using these tags was due to two reasons: the possibility of grouping problems and to make the analysis process easier. The tagging process was performed on the collaborative tool Lookback by two evaluators in order to achieve more reliable results and instigate the discussion of the problems encountered by the participants.

After the tagging process we grouped all tags by activity and with this information, it was possible to generate a chart with the occurrence of the tags by each activity as can be seen in Figure 2 .

\section{Findings}

The findings of this study are divided into two sections: one is by the point of view of the participant that answered the SAM questionnaire and the other reflects the researcher perspective, that is composed by the results of the observation form and the video analysis with CEM tags.

\subsection{User Perspective}

By looking at the data distribution on Figure 1 it can be observed that some Design Patterns were better evaluated in terms of satisfaction and dominance than others. As a matter of fact, the patterns Input Area, Button and Form Selection were the only ones with satisfaction and dominance without scores below five (where five is neutral). On the other hand, the patterns Toggle Menu, Icon, Infinite List and Vertical List had worse results.
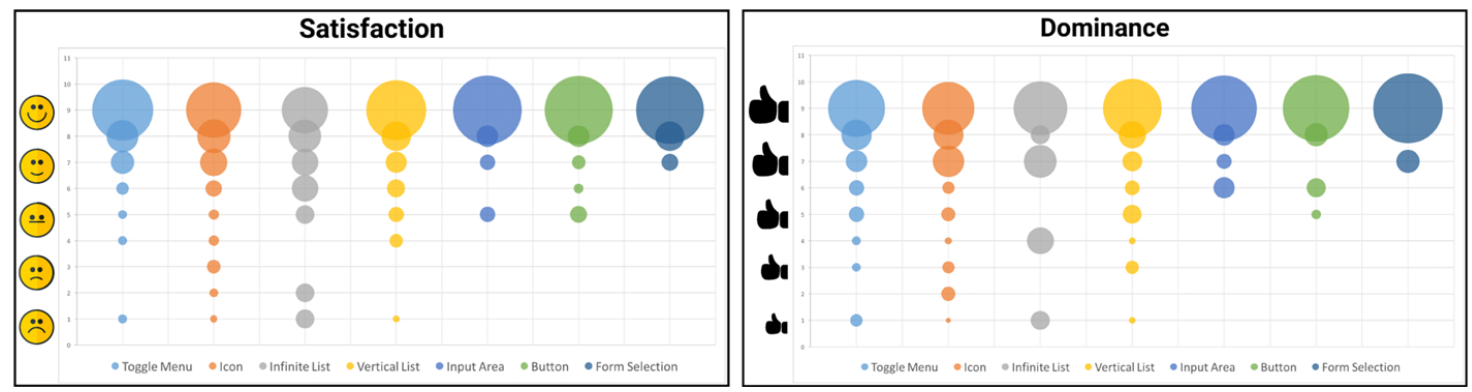

Figure 1. Feeling of Satisfaction and Dominance by Design Patterns

Based on these results we can also see that in all patterns the majority of the answers given by the participants float around 9 and 8 , which means extreme satisfaction and dominance. This is expected due to the fact that the participants did not have disabilities and only some of the participants would encounter barriers while using one or another element.

It's also clear that the same patterns that had poor satisfaction, also had higher incidence of negative (below five) dominance, which means that the overall emotion of the participants while using these patterns was negatively affected.

\subsection{Researcher Perspective}

The researcher perspective is oriented by activities and not by patterns, but the correlation with the user perspective can be easily noticed. In Figure 2 all 5 activities (ATs) are represented and we can see that Activity 1 had the highest occurrence of the Help tag. This can be explained by the fact that it was the first contact of the participants with 
V Congresso Brasileiro de Informática na Educação (CBIE 2016)

Anais do XXVII Simpósio Brasileiro de Informática na Educação (SBIE 2016)

the application and also because to complete the task the participants needed to navigate through the menu (Toggle Menu) of the application without knowing which options would be available. Still on the first activity, there is a significant high occurrence of Where am I? and Where is it? tags, which reinforces the argumentation.

On the second activity there was a high occurrence of Where is it? tag followed by Where am I?, What now? and Oops. This means that in this activity, that was mainly related with the use of Icon design pattern, the participants had great difficulty on understanding the meaning of some icons and figures used to represent actions in the application, making it harder to find actions and complete the activity.

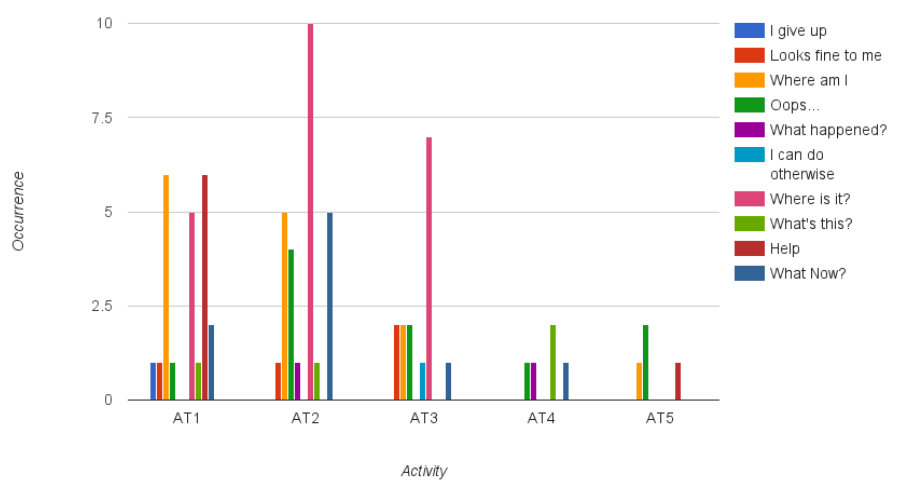

Figure 2. Occurrence of CEM tags by activity

The third activity had a high occurrence of the Where is it? tag. This activity was mainly related with the use of Infinite List pattern, which helps to explain the low satisfaction and dominance of this pattern by the fact that the participants had trouble finding a specific item of the list (that was conveniently located near the end of the list).

The other two activities did not present high occurrence of any tag, which can be explained by two factors: (i) by the time the participants executed these activities they had already explored great part of the application and (ii) the design patterns related to these activities where the ones with highest rates of satisfaction and dominance (Input Area, Button and Form Selection).

Finally, the observation form used by the evaluators during the experiment also had important annotations that helped to better understand the occurrence of tags and the emotion feedback.

\section{Discussion}

From both user and researcher perspectives it can be observed that there weren't identified major problems with the patterns Input Area, Button and Form Selection. One of the reasons for this to happen is that these patterns are well known interface elements that can be found in most web pages and thus, the participants were used with the mobile adaptation of such elements as reflected with positive satisfaction and dominance and also by the lack of CEM tags identified in the videos and problems related by the observers which indicates low accessibility problems.

On the other hand, the Infinite List pattern presented lower satisfaction and dominance amongst the participants which is explained by the video analysis where it was 
V Congresso Brasileiro de Informática na Educação (CBIE 2016)

Anais do XXVII Simpósio Brasileiro de Informática na Educação (SBIE 2016)

identified that some participants did not understand the continuous loading for new information at the end of the list and were frustrated for not finding the correct list item (some participants even gave up on the task). This is a serious accessibility barrier that the participants had to face and directly affected in their mood during the experiment.

Also, participants had difficulty understanding the meaning of Icons and were troubled by the Toggle Menu. In the recordings it was possible to see that the participants would open and close the menu several times in order to find the desired option in its Vertical List. These problems impacted in the time consumed during the tasks and also in the mood of the participants: it was possible to see the frustration of not finding an option and the need for help from the evaluator in order to complete the task.

A possible comparison between the problem of finding information in a Toggle Menu with visually impaired users can be identified: when a blind user or a user with low-vision access an application, he doesn't know which options a menu offers and needs to access item per item to understand the available features; when a user without disabilities access an interface with a toggle menu, he also doesn't know which features are present in the menu, in fact the user needs to identify the icon or text that represent the trigger for the menu and only them he will be able to see the which options are available [Yesilada et al. 2011].

The accessibility barriers encountered by the participants during the experiment are problematic as they can directly impact the usage of the e-learning platform in a mobile device. One must consider that during the experiment the participants could ask for help when they had issues with some interface element, but that this help would not be at hand if they were using the application in a real life scenario which could spoil their learning experience and prejudice their educational performance.

While the use of mobile devices to access educational environments provide easy access to information anywhere, anytime, accessibility problems as the described can jeopardize the process of knowledge acquisition, leading to further issues that could discourage users from using m-learning platforms. Also, by the time this article was written, we could not find any work that analysed the accessibility of Moodle for mobile devices which makes this study an important contribution for developers and designers that work with Moodle on mobile.

\section{Conclusion and Future Works}

The main goal of this study was to evaluate the accessibility of interaction design patterns on m-learning platforms based on emotional factors with users without disabilities. The results confirmed the initial idea that accessibility barriers would also affect the experience of users without disabilities while using the mobile application for Moodle.

There were noticed problems with the interaction with the application and these problems were mapped to Design Patterns and later investigated using recordings of the screen and face of the participants. The major issues were related with finding information or identifying the meaning of interface elements that directly affected in the participant's performance.

This study was conducted in a controlled environment with 21 participants (without disabilities) that were familiar with Moodle e-learning platform and did not have 
V Congresso Brasileiro de Informática na Educação (CBIE 2016)

Anais do XXVII Simpósio Brasileiro de Informática na Educação (SBIE 2016)

previous experience with the Moodle Mobile application. Because of this, the results are not as expressive as they would be if the experiment had been performed with disabled users, however, this was intentional.

Further research with other user groups with different types of disabilities (elderly and visually and hearing impaired users) on the m-learning system Moodle are planned in the near future in order to better understand the problem of the impact of accessibility related to design patterns on m-learning systems and to propose viable solutions that can be used by any developer or designer and applied to the widest variety of users, contexts and devices.

\section{References}

[Abachi and Muhammad 2014] Abachi, H. R. and Muhammad, G. (2014). The impact of m-learning technology on students and educators. Computers in Human Behavior, 30:491-496.

[Abou-Zahra et al. 2013] Abou-Zahra, S., Brewer, J., and Henry, S. L. (2013). Essential Components of Mobile Web Accessibility. In Proceedings of the 10th International Cross-Disciplinary Conference on Web Accessibility - W4A '13, pages 1-4.

[Ally and Prieto-Blázquez 2014] Ally, M. and Prieto-Blázquez, J. (2014). What is the future of mobile learning in education? Revista de Universidad y Sociedad del Conocimiento, 11(1):142-151.

[Barbosa et al. 2015] Barbosa, G., Oliveira, E., and Penna, J. (2015). Apreciação da usabilidade do moodle: Um estudo de caso no contexto do ensino fundamental. In Anais do Simpósio Brasileiro de Informática na Educação, volume 26, page 712.

[Bradley and Lang 1994] Bradley, M. M. and Lang, P. J. (1994). Measuring emotion: The self-assessment manikin and the semantic differential. Journal of Behavior Therapy and Experimental Psychiatry, 25(1):49 - 59.

[Brajnik 2008] Brajnik, G. (2008). Beyond conformance: the role of accessibility evaluation methods. In Web Information Systems Engineering-WISE 2008 Workshops, pages 6380. Springer.

[Capelão et al. 2011] Capelão, L., Coutinho, F., Pereira, K., and Prates, R. (2011). Avaliação de comunicabilidade do moodle para usuários surdos e ouvintes. Competição de avaliação do IHC \& CLIHC.

[Díaz-Bossini and Moreno 2013] Díaz-Bossini, J. M. and Moreno, L. (2013). Accessibility to mobile interfaces for older people. Procedia Computer Science, 27(2013):57-66.

[Guterres and Silveira 2015] Guterres, J. and Silveira, M. (2015). Desafios e novas possibilidades de uso de learning management systems. In Anais do Simpósio Brasileiro de Informática na Educação, volume 26, page 21.

[Harper et al. 2014] Harper, S., Thiessen, P., and Yesilada, Y. (2014). Research Report on Mobile Web Accessibility. Technical report, W3C.

[Henry et al. 2014] Henry, S. L., Abou-Zahra, S., and Brewer, J. (2014). The role of accessibility in a universal web. In Proceedings of the 11th Web for All Conference, W4A '14, pages 17:1-17:4, New York, NY, USA. ACM. 
V Congresso Brasileiro de Informática na Educação (CBIE 2016)

Anais do XXVII Simpósio Brasileiro de Informática na Educação (SBIE 2016)

[Heumann 1998] Heumann, J. (1998). Keynote address to Microsoft employees and experts on disabilities and technologyl. Redmond, Washington, February 19, 1998.

[Hoober and Berkman 2011] Hoober, S. and Berkman, E. (2011). Designing mobile interfaces. O'Reilly Media, Inc.

[Jemni et al. 2014] Jemni, M., Laabidi, M., and Jemni Ben Ayed, L. (2014). The New Development of Technology Enhanced Learning: Concept, Research and Best Practices, chapter Accessible E-learning for Students with Disabilities: From the Design to the Implementation, pages 53-74. Springer Berlin Heidelberg, Berlin, Heidelberg.

[Lazar et al. 2010] Lazar, J., Feng, J. H., and Hochheiser, H. (2010). Research Methods in Human-Computer Interaction. Wiley Publishing.

[Mazetto 2015] Mazetto, L. (2015). Uso do smartphone para acesso à internet cresce 112\% no Brasil. http://computerworld.com.br/uso-do-smartphone-para-acesso-internetcresce-112-no-brasil (Accessed on 03/14/2016).

[Moodle.org 2016] Moodle.org (2016). Moodle statistics. https://moodle.net/stats/ (Accessed on $05 / 28 / 2016$ ).

[Newell and Gregor 1988] Newell, A. and Gregor, P. (1988). Human computer interaction for people with disabilities. In Helandar, M. G., Landauer, T. K., and Prabhu, P. V., editors, Handbook of Human-Computer Interaction, pages 813-824. Elsevier Science Publishers, B. V., New York.

[Nielsen 2016] Nielsen (2016). 68 milhões usam a internet pelo smartphone no brasil. http://www.nielsen.com/br/pt/press-room/2015/68-milhoes-usam-a-internetpelo-smartphone-no-Brasil.html (Accessed on 03/14/2016).

[Pascual et al. 2013] Pascual, A., Ribera, M., Granollers, T., and Coiduras, J. L. (2013). Impact of accessibility barriers on the mood of blind, low-vision and sighted users. Procedia Computer Science, 27(2013):431-440.

[Ribeiro 2012] Ribeiro, J. (2012). Web Design Patterns for Mobile Devices. Master's thesis, Faculdade de Engenharia da Universidade do Porto.

[Ribeiro and Carvalhais 2012] Ribeiro, J. and Carvalhais, M. (2012). Web design patterns for mobile devices. In Proceedings of the 19th Conference on Pattern Languages of Programs, PLoP'12, pages 13:1-13:48, USA. The Hillside Group.

[Sampaio 2013] Sampaio, A. I. (2013). Responsive Web Design. Master's thesis, Escola de Engenharia, Universidade do Minho.

[Santana et al. 2014] Santana, M. A., dos Santos Neto, B. F., and de Barros Costa, E. (2014). Avaliando o uso das ferramentas educacionais no ambiente virtual de aprendizagem moodle. In Anais do Simpósio Brasileiro de Informática na Educação, volume 25, page 278 .

[Yesilada et al. 2011] Yesilada, Y., Brajnik, G., and Harper, S. (2011). Barriers common to mobile and disabled web users. Interacting with Computers, 23(5):525-542. 